\title{
The in vitro and in vivo anti-melanoma effects of hydroxyapatite nanoparticles: influences of material factors
}

This article was published in the following Dove Medical Press journal: International Journal of Nanomedicine

\author{
Hongfeng $\mathrm{Wu}^{\prime}$ \\ Zhongtao $\mathrm{Li}^{2}$ \\ Jiaoqing Tang ${ }^{2}$ \\ Xiao Yang' \\ Yong Zhou ${ }^{3}$ \\ Bo Guo ${ }^{4}$ \\ Lin Wang ${ }^{2}$ \\ Xiangdong Zhu' \\ Chongqi Tu ${ }^{3}$ \\ Xingdong Zhang' \\ 'National Engineering Research \\ Center for Biomaterials, Sichuan \\ University, Chengdu 610064, China; \\ ${ }^{2}$ Department of Dermatology, West \\ China Hospital of Sichuan University, \\ Chengdu 6I004I, China; ${ }^{3}$ Department \\ of Orthopaedics, West China Hospital \\ of Sichuan University, Chengdu \\ 6I004I, China; ${ }^{4}$ Department of \\ Ophthalmology, West China Hospital \\ of Sichuan University, Chengdu \\ 61004I, China
}

Background: Treatment for melanoma is a challenging clinical problem, and some new strategies are worth exploring.

Purpose: The objective of this study was to investigate the in vitro and in vivo anti-melanoma effects of hydroxyapatite nanoparticles (HANPs) and discuss the involved material factors.

Materials and methods: Five types of HANPs, ie, HA-A, HA-B, HA-C, HA-D, and HA-E, were prepared by wet chemical method combining with polymer template and appropriate post-treatments. The in vitro effects of the as-prepared five HANPs on inhibiting the viability of A375 melanoma cells and inducing the apoptosis of the cells were evaluated by Cell Counting Kit-8 analysis, cell nucleus morphology observation, flow cytometer, and PCR analysis. The in vivo anti-melanoma effects of HANPs were studied in the tumor model of nude mice. Results: The five HANPs had different physicochemical properties, including morphology, size, specific surface area (SSA), crystallinity, and so on. By the in vitro cell study, it was found that the material factors played important roles in the anti-melanoma effect of HANPs. Among the asprepared five HANPs, HA-A with granular shape, smaller size, higher SSA, and lower crystallinity exhibited best effect on inhibiting the viability of A375 cells. At the concentration of $200 \mu \mathrm{g} / \mathrm{mL}$, HA-A resulted in the lowest cell viability $(34.90 \%)$ at day 3. All the HANPs could induce the apoptosis of A375 cells, and the relatively higher apoptosis rates of the cells were found in HA-A (20.10\%) and HA-B (19.41\%) at day 3. However, all the HANPs showed no inhibitory effect on the viability of the normal human epidermal fibroblasts. The preliminary in vivo evaluation showed that both HA-A and HA-C could delay the formation and growth speed of melanoma tissue significantly. Likely, HA-A exhibited better effect on inhibiting the growth of melanoma tissue than HA-C. The inhibition rate of HA-A for tumor tissue growth reached $49.1 \%$ at day 23 . Conclusion: The current study confirmed the anti-melanoma effect of HANPs and provided a new idea for the clinical treatment of melanoma.

Keywords: hydroxyapatite, nanoparticles, melanoma cells, fibroblasts, viability, apoptosis, tumor, suppression

Correspondence: Bo Guo

Department of Ophthalmology,

West China Hospital of Sichuan

University, No. 37 Guo Xue Xiang,

Chengdu 61004I, China

Tel +862885422542

Email guobohx@163.com

Xiangdong Zhu

National Engineering Research Center for Biomaterials, Sichuan University, No. 29

Wangjiang Road, Chengdu 610064, China

Tel +862885470770

Email zhu_xd1973@scu.edu.cn

submit your manuscript

Dovepress if $y$

http:/

International Journal of Nanomedicine 2019:|4 | |77-1 |9|

II77

(c) (1) (5) 2019 Wu et al. This work is published and licensed by Dove Medical Press Limited. The full terms of this license are available at https://www.dovepress.com/terms.php cc) ${ }_{\mathrm{BY}} \mathrm{NC}$ and incorporate the Creative Commons Attribution - Non Commercial (unported, v3.0) License (http://creativecommons.org/licenses/by-nc/3.0/). By accessing the work you hereby accept the Terms. Non-commercial uses of the work are permitted without any further permission from Dove Medical Press Limited, provided the work is properly attributed. For permission for commercial use of this work, please see paragraphs 4.2 and 5 of our Terms (https://www.dovepress.com/terms.php). 
rapid proliferation, local invasion, long-distance migration, and strong resistance to currently clinical therapies. ${ }^{1,10}$ Except the thin primary skin melanoma $(<1 \mathrm{~mm})$, the clinical surgery for metastatic melanoma and deep primary malignant melanoma $(>4 \mathrm{~mm})$ still have a very high recurrence rate and mortality. ${ }^{11,12}$ Therefore, new strategies for improving the clinical treatment effect of melanoma are quite necessary.

Hydroxyapatite (HA) is a major inorganic component of human bone and teeth, and exhibits excellent biocompatibility, bioactivity, osteoconduction, and even osteoinduction in biomedical application. ${ }^{13-15}$ In 1990s, Aoki et al and Kano et al first reported the in vitro anti-tumor effect of HA nanoparticles (HANPs). ${ }^{16,17}$ They occasionally found that HANPs without loading doxorubicin still had the inhibitory effect on the proliferation for Ca-9 tumor cells. After that, the anti-tumor effects of HANPs were widely regarded and investigated. A large number of reports indicated that HANPs could inhibit the proliferation of various tumor cells, such as hepatoma cells, ${ }^{18-20}$ osteosarcoma cells, ${ }^{21-23}$ lung cancer cells, ${ }^{24,25}$ and gastric cancer cells ${ }^{26-28}$ to some extent. Moreover, HANPs showed little or no inhibitory effect on the normal tissue cells, including osteoblasts, ${ }^{23}$ hepatocytes, ${ }^{18}$ lung fibroblasts, ${ }^{25}$ etc. This was undoubtedly hopeful to overcome the drawbacks of some anti-tumor drugs, which could kill cancer cells as well as normal tissue cells.

In previous studies, Li et al reported that HANPs had certain anti-melanoma effect. ${ }^{29}$ They found that for HANPs, the size had stronger influence on the proliferation of A875 melanoma cells than the morphology. However, the involved mechanism has not been well revealed. Besides, the correlation between the material factors of HANPs and proliferation inhibition or apoptosis of melanoma cells need be further investigated. Hence, in the present study, we prepared five different HANPs by wet chemical method combining with polymer template and different post-treatments, and investigated their anti-melanoma effects by in vitro and in vivo experiments. Besides, human fibroblasts were chosen as the control to investigate their impacts on normal tissue cells. The influences of various material factors on the anti-melanoma effects of the HANPs were studied systematically and discussed.

\section{Materials and methods}

\section{Reagents}

$\mathrm{Ca}\left(\mathrm{NO}_{3}\right)_{2} \cdot 4 \mathrm{H}_{2} \mathrm{O},\left(\mathrm{NH}_{4}\right)_{2} \mathrm{HPO}_{4}$, and $\mathrm{NH}_{3} \cdot \mathrm{H}_{2} \mathrm{O}$ were purchased from Sinopharm Chemical Reagent Co., Ltd. (Shanghai, China). PEG2000 was purchased from the Aladdin (Shanghai, China). Human melanoma cells (A375) and human epidermal fibroblasts (HSF) were purchased from iCell Bioscience Inc (Shanghai, China). FBS, DMEM medium, penicillin-streptomycin solution, PBS, and Trypsin $0.25 \%$ EDTA were purchased from Thermo Fisher Scientific (Waltham, MA, USA). Fluorescein diacetate and propidium iodide (PI) were purchased from SigmaAldrich Co. (St Louis, MO, USA). DAPI was purchased from Beyotime (Shanghai, China). Cell Counting Kit-8 (CCK-8) was purchased from Dojindo Laboratories (Kumanoto, Japan). Fluorescein isothiocyanate (FITC) Annexin V Apoptosis Detection Kit I was purchased from BD (Franklin Lakes, NJ, USA). The RNeasy Mini Kit was purchased from Qiagen (Hilden, Germany). The iScript ${ }^{\mathrm{TM}}$ gDNA Clear cDNA Synthesis kit and SsoFast ${ }^{\mathrm{TM}}$ EvaGreen Supermix were purchased from BioRad Laboratories Inc. (Hercules, CA, USA). The Matrigel was purchased from Corning Incorporated (Corning, NY, USA).

\section{Preparation of HANPs}

HANPs were synthesized at room temperature by wet chemical method using reactive system of $\mathrm{Ca}\left(\mathrm{NO}_{3}\right)_{2} \cdot 4 \mathrm{H}_{2} \mathrm{O}$ and $\left(\mathrm{NH}_{4}\right)_{2} \mathrm{HPO}_{4}$, in which $\mathrm{NH}_{3} \cdot \mathrm{H}_{2} \mathrm{O}$ was used for $\mathrm{pH}$ adjustment and PEG2000 as a template reagent. The molar ratio of $\mathrm{Ca} / \mathrm{P}$ was maintained at 1.67. A certain amount of PEG2000 solution $(8.0 \mathrm{wt} \%)$ was added to $\mathrm{Ca}\left(\mathrm{NO}_{3}\right)_{2} \cdot 4 \mathrm{H}_{2} \mathrm{O}$ solution, and then $\left(\mathrm{NH}_{4}\right)_{2} \mathrm{HPO}_{4}$ solution was added dropwise to the solution, whose $\mathrm{pH}$ was kept at $\sim 10.0$ by addition of $\mathrm{NH}_{3} \cdot \mathrm{H}_{2} \mathrm{O}$. After that, the stirring for mixing the solution continued for a period of time, and then the slurry was aged at room temperature for 24 hours. Next, the slurries were washed with ultrapure water to neutrality. With or without post-treatment, the slurries were dried at $60^{\circ} \mathrm{C}$ for 10 hours. Various preparing parameters for HANPs, including the concentration of reactants and the post-treatment of the slurries are summarized in Table 1. In total, five HANPs, ie, HA-A, HA-B, HA-C, HA-D, and HA-E, were prepared for subsequent experiments.

Table I The preparing parameters for the five HANPs

\begin{tabular}{l|l|l}
\hline Samples & $\mathrm{Ca}^{2+}$ concentration & Post-treatment \\
\hline HA-A & $0.50 \mathrm{M}$ & Drying directly at $60^{\circ} \mathrm{C}$ in an oven \\
HA-B & $0.50 \mathrm{M}$ & Hydrothermal treatment at $120^{\circ} \mathrm{C}$ for 12 hours, then drying at $60^{\circ} \mathrm{C}$ in an oven \\
HA-C & $0.50 \mathrm{M}$ & Hydrothermal treatment at $150^{\circ} \mathrm{C}$ for 12 hours, then drying at $60^{\circ} \mathrm{C}$ in an oven \\
HA-D & $0.50 \mathrm{M}$ & Drying at $60^{\circ} \mathrm{C}$ in an oven, then calcinating at $700^{\circ} \mathrm{C}$ for I hour in a muffle furnace \\
HA-E & $0.10 \mathrm{M}$ & Drying directly at $60^{\circ} \mathrm{C}$ in an oven \\
\hline
\end{tabular}

Abbreviation: HANP, hydroxyapatite nanoparticle. 


\section{Characterization of HANPs}

The phase composition of HANPs was determined by X-ray diffraction (XRD, Shimazu XRD-6100, Kyoto, Japan) using $\mathrm{Cu}$ Ka radiation $(\lambda=1.5418 \AA$ ) with the test voltage at $40 \mathrm{kV}$ and the operating current at $30 \mathrm{~mA}$. The diffraction spectrum was scanned from $20^{\circ}$ to $60^{\circ}$ with a speed of $5^{\circ} / \mathrm{min}$. Patterns were analyzed by using Jade 6.0 software. The crystallinity of HANPs was calculated using the following Equation 1, where $\beta_{002}$ is the full width at half maximum of the (002)..$^{30,31}$

$$
X_{c}=\left(0.24 / \beta_{002}\right)^{3}
$$

The chemical groups of HANPs were analyzed by Fouriertransform infrared spectroscopy (FTIR, Nicolet 6700; Thermo Fisher Scientific) with the range from 4,000 to $400 \mathrm{~cm}^{-1}$.

The morphology and particle size of HANPs were observed by Transmission Electron Microscope (TEM, FEI; Tecnai G2F20, Hillsboro, OR, USA) at the working voltage of $200 \mathrm{kV}$. The morphology of the NPs was observed by dropping HANPs dissolved onto a copper grid. The particle size of HANPs was measured by using Nano Measurer. When measuring the particle sizes, we selected at least three images of as-prepared five HANPs at the scale of $200 \mathrm{~nm}$, and at least 70 particles in each image were evaluated for statistical analysis.

Zeta potentials of HANPs were measured by a Nano Zetasizer (ZS90; Malvern Instruments, Malvern, UK) based on dynamic light scattering theory. The specific surface areas (SSAs) of HANPs were determined by Brunauer-EmmettTeller method using a surface area analyzer (GeminiVII 2390 t; Micromeritics Instrument Corporation, Norcross, GA, USA). The releases of $\mathrm{Ca}^{2+}$ from HANPs were measured by ICP-AES (ARCOS; Spectro Analytical Instruments GmbH, Kleve, Germany). Simply, the five HANPs were dispersed in Tris- $\mathrm{HCl}$ solution (pH7.4) at the concentration of $200 \mu \mathrm{g} / \mathrm{mL}$ and then placed in a $37^{\circ} \mathrm{C}$ incubator for 3 days. Next, the supernatants were collected and analyzed.

\section{Cell culture}

Both A375 and HSF cells were cultured in DMEM medium supplemented with $1 \%$ penicillin and streptomycin and $10 \%$ FBS at $37^{\circ} \mathrm{C}$ under $5 \% \mathrm{CO}_{2}$ atmosphere. After the cells grew to $70 \%-80 \%$ confluence in tissue culture flasks, the cells were digested with $0.25 \%$ trypsin containing EDTA and counted, followed by seeding in a 24-well plate with a density of $10^{4}$ cells per well. The HANPs suspensions with different concentrations $(100,200$, and $400 \mu \mathrm{g} / \mathrm{mL})$ were prepared by dispersing the NPs in DMEM. After cell attachment, the HANPs suspension was added into each well. Then, the cells were subjected to the subsequent analysis after culturing for 1,2, and 3 days.

\section{CCK-8 analysis}

Cell viability was evaluated by CCK- 8 method. After culturing A375 or HSF cells with various HANPs for the set times, the media were removed, followed by addition of fresh DMEM medium, including water-soluble tetrazolium (WST)-8 (WST-8/DMEM =1/9). After keeping in a dark place for 2 hours, the OD value in all wells were measured by a microplate reader (EON; BioTek, Winooski, VT, USA) at the wavelength of $450 \mathrm{~nm}$. The cells without addition of HANPs were used as the control group. Three duplicates for each group were used in the test, and cell viability (\%) was calculated according to Equation 2.

$$
\text { Cell viability }(\%)=\frac{[\mathrm{OD}]_{\text {test }}-[\mathrm{OD}]_{\text {blank }}}{[\mathrm{OD}]_{\text {control }}-[\mathrm{OD}]_{\text {blank }}}
$$

\section{Confocal laser scanning microscopy (CLSM) observation}

After culturing A375 or HSF cells with various HANPs for the set times, the media were removed, then the cells were washed with PBS (pH 7.4) and fixed with 4\% paraformaldehyde for 20 minutes, followed by staining with DAPI for 10 minutes in the dark. The nuclear morphology of the cells was examined by CLSM (Leica-TCS-SP5; Leica Microsystems, Wetzlar, German), and the cell nucleus was dyed blue.

\section{Flow cytometer}

The apoptosis of A375 cells was analyzed by flow cytometer (CytoFLEX; Beckman Coulter, Guangzhou, China). After culturing with the HANPs for the set times, the cells were double stained with Annexin V FITC/PI. The normal, apoptotic, and necrotic cells were examined. FITC and PI staining were performed according to the manufacturer's instructions. A375 cells in different states were mapped in a bidirectional dot plot.

\section{PCR analysis}

After culturing with the HANPs for the set times, RNA of the cells (A375 or HSF) was isolated using RNeasy Mini Kit. The cells were fully lysed using Buffer RLT, and the centrifuged RNA samples were added to the DNase reagent to remove genomic DNA contamination. The extracted RNA was reversely transcribed into cDNA using the iScriptTM gDNA Clear cDNA kit. The resulting cDNA was then amplified using the SsoFastTM EvaGreen ${ }^{\circledR}$ kit. Three parallel samples were set for each target gene. The PCR reaction was performed using a CFX $96^{\mathrm{TM}}$ system (Bio-Rad), and the data were processed and analyzed by CFX Manager software. 
Table 2 The primer sequences for the apoptotic-related genes

\begin{tabular}{|c|c|c|c|}
\hline Gene & Primer & Sequence $\left(5^{\prime}\right.$ to $\left.3^{\prime}\right)$ & Gene bank identification \\
\hline GAPDH & $\begin{array}{l}\text { Forward } \\
\text { Reverse }\end{array}$ & $\begin{array}{l}\text { GCCAAGGCTGTGGGCAAGGT } \\
\text { AGGTGGAGGAGTGGGTGTCG }\end{array}$ & NM_002046 \\
\hline Caspase-3 & $\begin{array}{l}\text { Forward } \\
\text { Reverse }\end{array}$ & $\begin{array}{l}\text { ATAAGGAAAGCAATAAATGAATGG } \\
\text { CAGTGCGTATGGAGAAATGGG }\end{array}$ & NM_03299I \\
\hline Caspase-8 & $\begin{array}{l}\text { Forward } \\
\text { Reverse }\end{array}$ & $\begin{array}{l}\text { TTTTATTCAGGCTTGTCAGGG } \\
\text { CTGGCAAAGTGACTGGATGTA }\end{array}$ & NM_00I 228.4 \\
\hline Caspase-9 & $\begin{array}{l}\text { Forward } \\
\text { Reverse }\end{array}$ & $\begin{array}{l}\text { TGGTTCTGGAGGATTTGGTGA } \\
\text { CGACGCCGCAACTTCTCACA }\end{array}$ & NM_00I229 \\
\hline $\mathrm{Bcl}-2$ & $\begin{array}{l}\text { Forward } \\
\text { Reverse }\end{array}$ & $\begin{array}{l}\text { TGCGTCCTACAGATACCACAA } \\
\text { ATGATGCCGTCTTCAAACTCC }\end{array}$ & NM_004049.3 \\
\hline Bax & $\begin{array}{l}\text { Forward } \\
\text { Reverse }\end{array}$ & $\begin{array}{l}\text { GCTTCAGGGTTTCATCCAGG } \\
\text { CACGGCGGCAATCATCCTCT }\end{array}$ & NM_I3876I \\
\hline p53 & $\begin{array}{l}\text { Forward } \\
\text { Reverse }\end{array}$ & $\begin{array}{l}\text { TGTGCCTTGCCAGTGGGATTC } \\
\text { AGGATTTTCACGGGGTTGCCA }\end{array}$ & NM_00II4I980 \\
\hline
\end{tabular}

Abbreviation: GAPDH, glyceraldehyde-3-phosphate dehydrogenase.

The target gene expression level was calculated by $2^{-\Delta \Delta \mathrm{Ct}}$ method, and glyceraldehyde-3-phosphate dehydrogenase was used as the internal reference gene to normalize the result. Primer sequences in the present study are shown in Table 2.

\section{Animal study}

In the present study, $15 \mathrm{BALB} / \mathrm{C}$ nude mice (female, 14-16 weeks old, weighing 20.0 $\pm 1.0 \mathrm{~g}$ ) purchased from Laboratory Animal Center of Sichuan University (Chengdu, China) were used for animal study. The animal experiments were approved by the Animal Care and Use Committee of Sichuan University and followed the guidelines of the Chinese Society of Laboratory Animals on animal welfare. The nude mice were randomly divided into three groups, ie, one control group and two experimental groups. Based on the aforementioned in vitro evaluation, HA-A and HA-C were selected as the experimental materials. According to $1 \mathrm{mg} / \mathrm{mL}$ concentration, the HANPs suspension was prepared by dispersing $50 \mathrm{mg}$ HANPs into $50 \mathrm{~mL}$ DMEM. After A375 cells grew to $70 \%-80 \%$ confluence in tissue culture flasks, the cells were trypsinized and the cell suspension was collected. Then, the cell suspension containing $2 \times 10^{6}$ cells were transferred into a centrifuge tube and centrifuged at the speed of 1,000 rpm, followed by adding $1 \mathrm{~mL}$ HANPs suspension (or DMEM for control group) and $10 \mu \mathrm{L}$ commercial Matrigel. The mixture was subcutaneously injected into the left side of the nude mouse after blending thoroughly. Therefore, the injection dose of HANPs in each mouse in the experimental groups was $50 \mathrm{mg} / \mathrm{kg}$ weight. The formation and volume change of tumor tissue in the animal was observed and recorded. The length and width of the formed tumor tissue in each animal and each time point were measured by caliper, and the tumor volume was calculated according to Equation 3:

$$
\text { Tumor volume }\left(\mathrm{mm}^{3}\right)=\mathrm{ab}^{2} / 2
$$

where $\mathrm{a}$ and $\mathrm{b}$ represented the largest length and width of the formed tumor tissue, respectively. ${ }^{32}$

\section{Statistical analysis}

Statistical analysis was performed with one-way ANOVA using SPSS13.0 software. All data were expressed as mean \pm SD and obtained by at least three replicates for each data set. The level of $P<0.05$ was considered to be statistically significant.

\section{Results \\ Characterization of HANPs}

Figure 1A shows the XRD patterns of the as-prepared five HANPs. The characteristic peaks in the five HANPs were consistent with those in the HA standard (JCPDS: 09-0432), indicating that all of them were composed of pure HA phase. In the three samples with different post-treatments (HA-B, HA-C and HA-D), the three diffraction peaks, which respectively corresponds with (211), (112) and (300) crystal faces, were obviously sharp. However, in other two directly dried samples (HA-A and HA-E), they were partly fused. Figure 1B shows the infrared spectra of the as-prepared five HANPs. In all the samples, two characteristic peaks corresponding with $\mathrm{OH}^{-}$and $\mathrm{PO}_{4}{ }^{3-}$ groups in $\mathrm{HA}$ could be seen clearly. The vibration peaks of $\mathrm{OH}^{-}$appeared at about $3,560 \mathrm{~cm}^{-1} \cdot{ }^{33}$ There were two weak peaks ranging from $550 \mathrm{~cm}^{-1}$ to $650 \mathrm{~cm}^{-1}$, which could be the stretching vibration peaks of $\mathrm{PO}_{4}{ }^{3-}$ bond. 

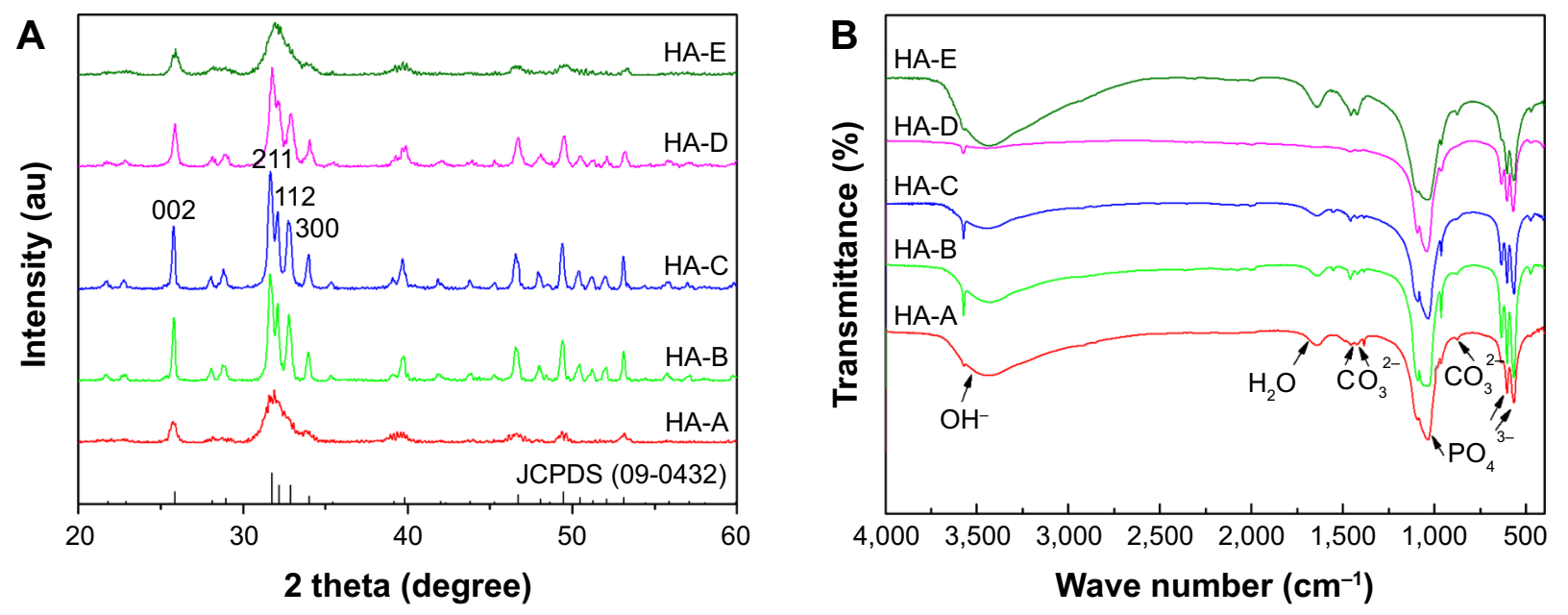

Figure I X-ray diffraction patterns $(\mathbf{A})$ and Fourier-transform infrared spectra $(\mathbf{B})$ of the as-prepared five HANPs. Abbreviation: HANP, hydroxyapatite nanoparticle.

The band between $1,120 \mathrm{~cm}^{-1}$ and $940 \mathrm{~cm}^{-1}$ belonged to the strong and broad peaks of $\mathrm{PO}_{4}{ }^{3-} \cdot 33,34$ Except for HA-D, the other four HANPs showed the characteristic peak of $\mathrm{CO}_{3}{ }^{2-}$ at about $1,460 \mathrm{~cm}^{-1}$ and $870 \mathrm{~cm}^{-1}$. This could be attributed to $\mathrm{CO}_{2}$ in the air entering the solution and participating in the precipitation of HANPs, leading to formation of B-HA. ${ }^{33-35}$ As for HA-D, the calcination process could result in the loss of $\mathrm{CO}_{3}{ }^{2-}$. Besides, there was a very weak tensile vibration peak at about $1,650 \mathrm{~cm}^{-1}$, indicating that the as-prepared HANPs could contain the crystal water. ${ }^{33,35}$

Figure 2 shows the TEM images of the as-prepared five HANPs, and Table 3 summarizes their physicochemical properties. They all were nano-scaled particles but had different morphologies and sizes. Both HA-A and HA-D had granular shapes, but their average particle sizes were about 20 and $50 \mathrm{~nm}$, respectively. HA-E was needle-like, and its average diameter and length were about 5 and $40 \mathrm{~nm}$, respectively. Both HA-B and HA-C were rod-like, but HA-B had a little larger diameter and length than HA-C. All the five HANPs had negative zeta potentials, indicating that they had negative surface net charges. Based on the XRD analysis, HA-A and HA-E had far lower crystallinity than the other three HANPs, indicating that the hydrothermal or calcinating process could improve the crystallization of the synthesized
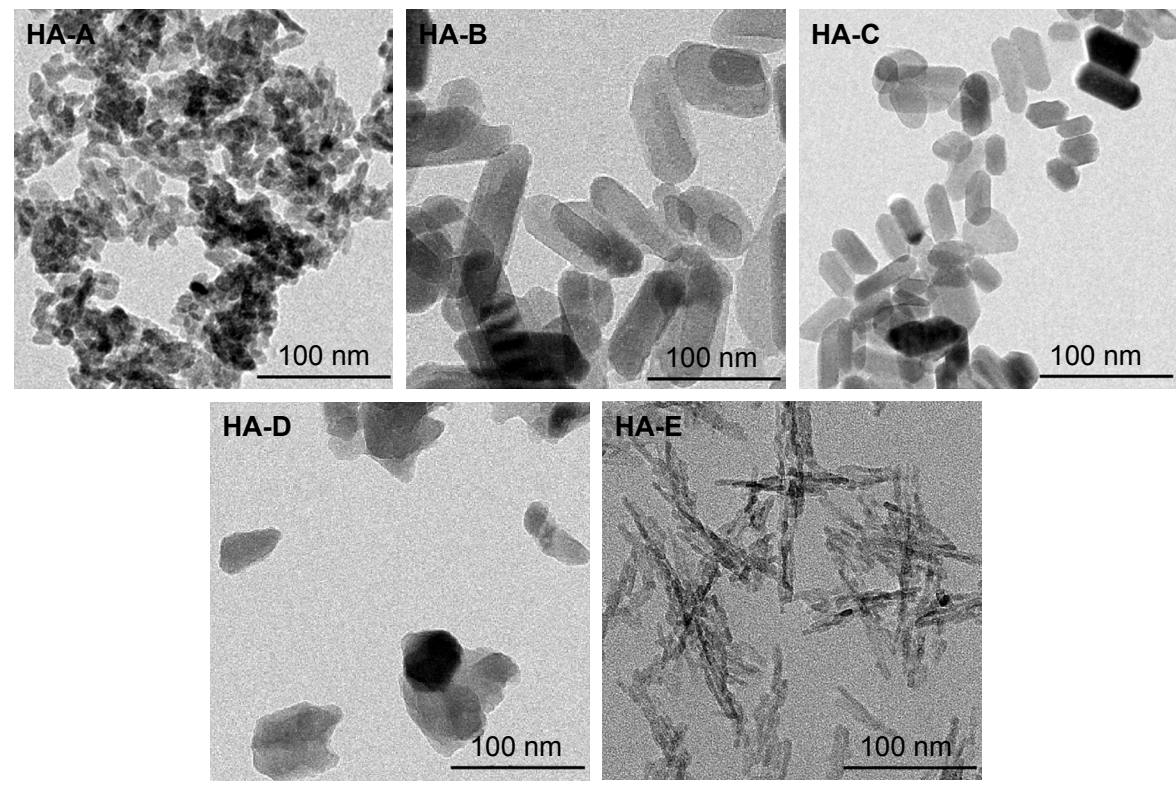

Figure 2 The typical transmission electron microscope images of the as-prepared five HANPs.

Abbreviation: HANP, hydroxyapatite nanoparticle. 
Table 3 The physicochemical properties of the as-prepared five HANPs

\begin{tabular}{|c|c|c|c|c|c|}
\hline \multirow{2}{*}{$\begin{array}{l}\text { Physicochemical } \\
\text { properties }\end{array}$} & \multicolumn{5}{|l|}{ Samples } \\
\hline & HA-A & HA-B & HA-C & HA-D & HA-E \\
\hline Morphology & Granular & Rod-like & Rod-like & Granular & Needle-like \\
\hline \multirow[t]{2}{*}{ Particle size (nm) } & $17.41 \pm 1.16$ & $L: 61.26 \pm 6.38$ & $\mathrm{~L}: 45.13 \pm 8.85$ & $47.58 \pm 7.04$ & $L: 39.29 \pm 6.05$ \\
\hline & & $D: 29.08 \pm 5.26$ & $D: 25.24 \pm 2.12$ & & 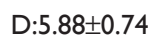 \\
\hline Crystallinity (\%) & 12.80 & 72.89 & 73.29 & 52.57 & 20.00 \\
\hline Zeta potential $(\mathrm{mV})$ & $-9.62 \pm 0.65$ & $-\mid 0.90 \pm 0.91$ & $-12.50 \pm 0.78$ & $-16.60 \pm 0.60$ & $-10.60 \pm 0.69$ \\
\hline $\operatorname{SSA}\left(\mathrm{m}^{2} / \mathrm{g}\right)$ & $107.38 \pm 0.06$ & $48.64 \pm 0.31$ & $51.27 \pm 7.19$ & $26.45 \pm 0.49$ & $89.90 \pm 16.87$ \\
\hline$\left[\mathrm{Ca}^{2+}\right](\mathrm{ppm})$ & $7.09 \pm 0.53$ & $2.82 \pm 0.03$ & $1.98 \pm 0.05$ & $2.92 \pm 0.06$ & $8.04 \pm 0.23$ \\
\hline
\end{tabular}

Abbreviation: HANP, hydroxyapatite nanoparticle.

HANPs. Likely, SSA of HANPs was also influenced by the post-treatments. HA-A and HA-E had far higher SSA than the other three HANPs. However, the calcinated HA-D had lower crystallinity and SSA than the hydrothermal treated HA-B and HA-C. Under two different hydrothermal treatments, no obvious difference of crystallinity and SSA was found between HA-B and HA-C.

\section{Cell viability}

Based on the CCK-8 analysis, cell viabilities of A375 cells after culturing with the HANPs are shown in Figure 3A. At three different HANPs concentration $(100,200$, and $400 \mu \mathrm{g} / \mathrm{mL}$ ), among the five HANPs, only HA-A presented the continuous inhibition on the viability of A375 cells, and the cell viability almost decreased with the increase of culturing time. For the other four HANPs, both HA-B and HA-C exhibited the continuous inhibition on the viability of A375 cells only at the concentration of $200 \mu \mathrm{g} / \mathrm{mL}$. It should be noted that the inhibitory effect of HANPs was not always positively related with the concentration of the nanoparticles. At day 3, almost all the HANPs showed the strongest inhibitory effect on the cell viability at the concentration of $200 \mu \mathrm{g} / \mathrm{mL}$.

Figure 3B shows the cell viabilities of normal HSF cells after culturing with the HANPs. It could be seen that for all the five HANPs, the cell viability almost increased with the increase of culturing time at each concentration, indicating that HANPs showed no inhibitory effect on the viability of HSF cells.

Table 4 gives the concrete cell viabilities of both types of cells after culturing with various HANPs at the concentration of $200 \mu \mathrm{g} / \mathrm{mL}$ for 3 days. It could be seen that HA-A led to the lowest cell viability of A375 cells (34.90\%), and HA-E resulted in the highest cell viability $(74.90 \%)$. The other three HANPs, ie, HA-B, HA-C, and HA-D, presented similar cell viabilities of $\mathrm{A} 375$ cells. On the contrary, all the HANPs except HA-C increased the viability of HSF cells significantly.

\section{Cell nucleus morphology}

Figure 4A shows the CLSM images of A375 cells stained with DAPI after culturing with various HANPs at the concentration of $200 \mu \mathrm{g} / \mathrm{mL}$ for 1 and 3 days. Some morphological changes in the cell nucleus could be easily observed. In control group, the cells were not observed to have obvious morphology change of the nucleus. But in the experimental groups, after culturing with HANPs for 1 day, the vacuoles were found occurring on the nuclear membrane. Also, the nuclear shrinkage or fragmentation were observed in some cells. When the culturing time increased to 3 days, more cells presented the phenomena of nuclear shrinkage and fragmentation, tending to apoptosis. ${ }^{36}$ Figure 4B shows the CLSM images of HSF cells stained with DAPI after culturing with various HANPs for 1 and 3 days. Either in the control or experimental groups, no obvious morphology change of cell nucleus could be found.

\section{Apoptosis rate of $\mathrm{A} 375$ cells}

To quantify the cell apoptosis, A375 cells were double stained with Annexin V FITC/PI and analyzed by flow cytometer after culturing with various HANPs at the concentration of $200 \mu \mathrm{g} / \mathrm{mL}$ for 1 and 3 days. The results are shown in Figure 5. For the control group, without addition of HANPs, only tiny apoptotic cells could be found, and the apoptosis rate of the cells was almost negligible. However, after culturing with HANPs, the apoptosis, especially early apoptosis of the cells was obvious and increased with the increase in culturing time in each experimental group. At day 3, the total apoptosis rates of A375 melanoma cells in HA-A, HA-B, HA-C, HA-D, and HA-E were $20.10 \%, 19.41 \%, 17.14 \%$, $12.84 \%$, and $16.39 \%$, respectively.

\section{Apoptosis-related gene expressions}

Figure 6A shows the apoptosis-related gene expressions in A375 cells after culturing with various HANPs at the 
A
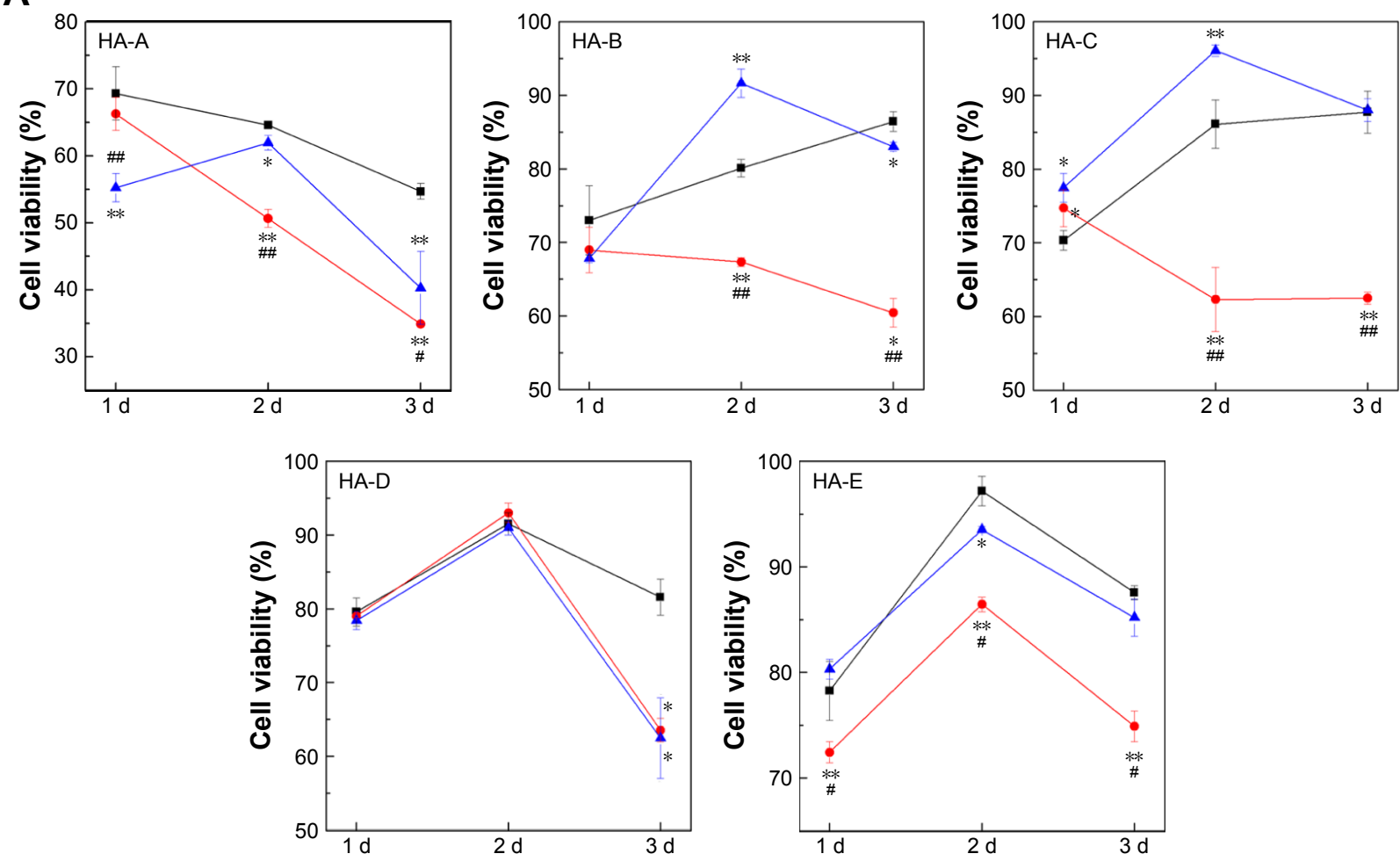

B
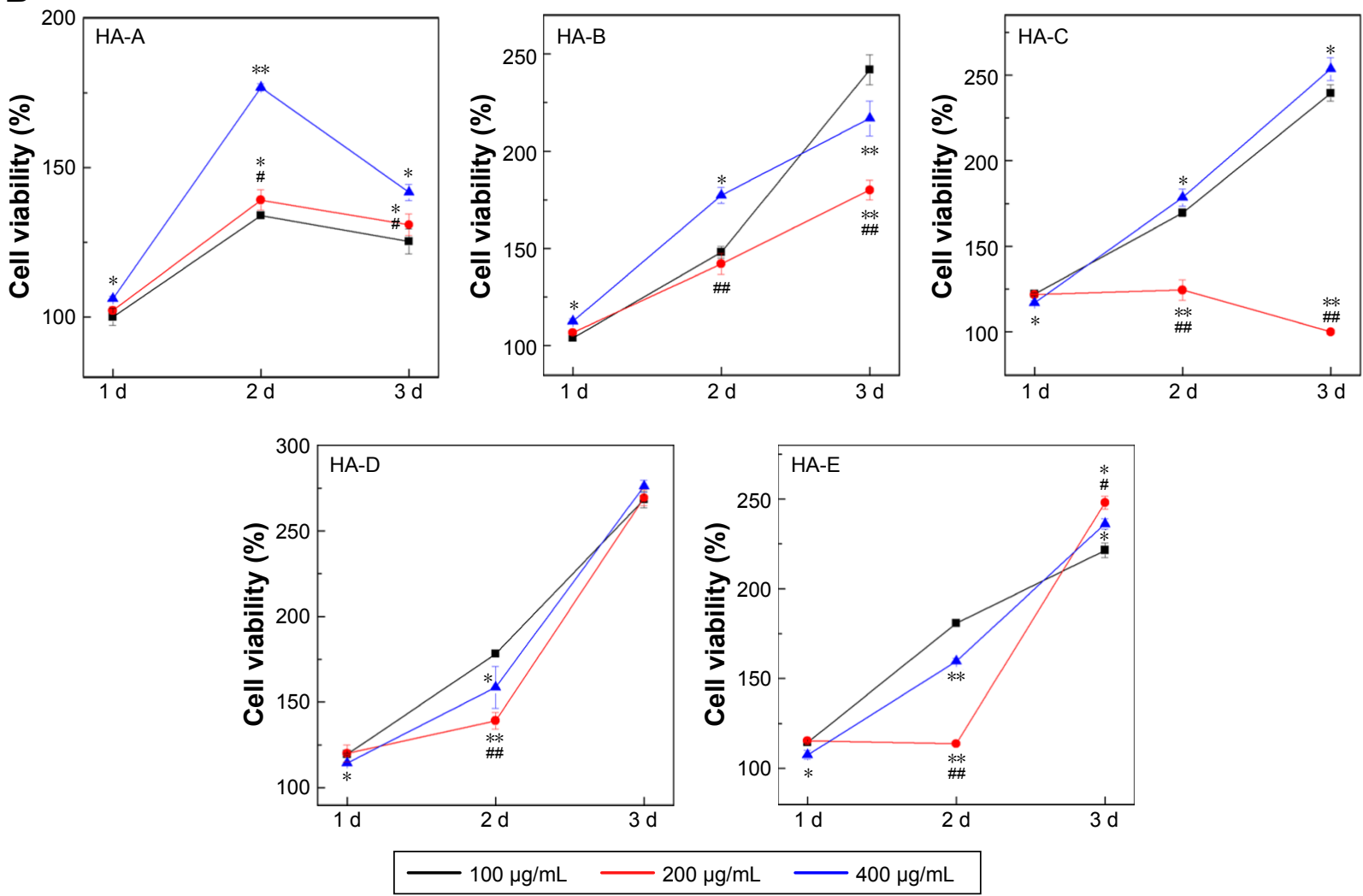

Figure 3 Changes of cell viabilities of $\mathrm{A} 375(\mathbf{A})$ and $\mathrm{HSF}(\mathbf{B})$ cells with the culturing time at different concentrations of $\mathrm{HANPs}$. ( $\mathrm{n}=3$; vs I00 $\mu \mathrm{g} / \mathrm{mL}$, $* P<0.05$, $* * P<0.0 \mathrm{I}$; vs $\left.400 \mu \mathrm{g} / \mathrm{mL},{ }^{\#} P<0.05,{ }^{\#} P<0.01\right)$.

Abbreviations: HANP, hydroxyapatite nanoparticle; HSF, human epidermal fibroblasts. 
Table 4 Cell viabilities of A375 cells after culturing with various HANPs at the concentration of $200 \mu g / m L$ for 3 days ( $n=3$ )

\begin{tabular}{l|l|l|l|l|l}
\hline \multirow{2}{*}{ Cell type } & \multicolumn{5}{l}{ Cell viability (\%) } \\
\cline { 2 - 6 } & HA-A & HA-B & HA-C & HA-D & HA-E \\
\hline A375 & $34.90 \pm 0.24$ & $60.43 \pm 1.96$ & $62.49 \pm 0.83$ & $63.54 \pm 1.60$ & $74.90 \pm 1.44$ \\
HSF & $130.77 \pm 3.61$ & $180.04 \pm 5.00$ & $100.00 \pm 1.50$ & $269.35 \pm 4.70$ & $248.06 \pm 3.68$ \\
\hline
\end{tabular}

Abbreviation: HANP, hydroxyapatite nanoparticle.
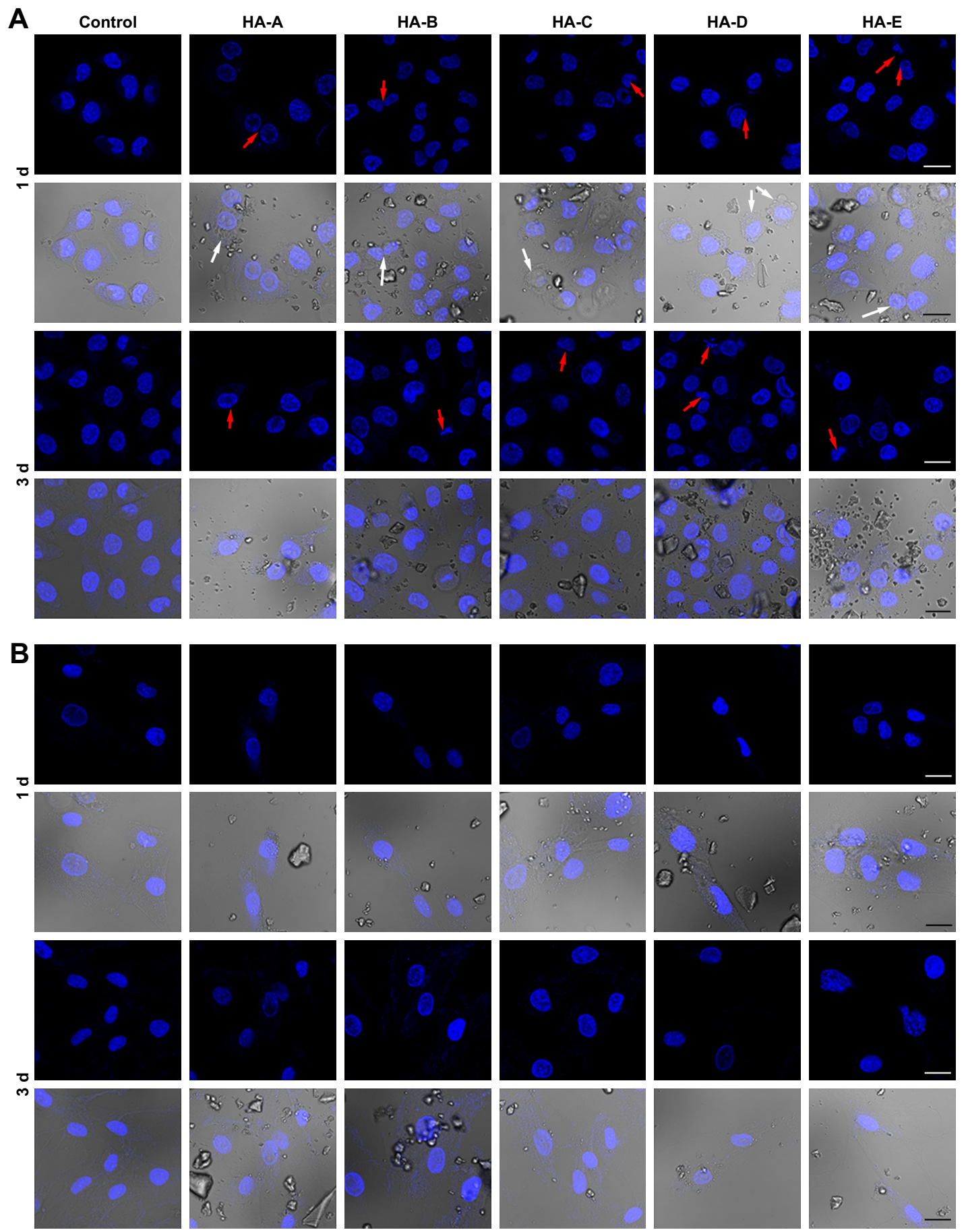

Figure 4 The typical CLSM images of A375 (A) and HSF (B) cells stained with DAPI (blue) after culturing with various HANPs at the concentration of $200 \mu \mathrm{g} / \mathrm{mL}$ for I and 3 days (both fluorescence field and superimposed pictures of the bright and fluorescence fields are given in the figure; magnification: $\times 100$; scale bars: $20 \mu \mathrm{m}$; white arrow: vacuoles presented on nuclear membrane; red arrows: nuclear shrinkage or fragmentation; the dispersed HANPs are seen in the superimposed pictures; three duplicates for each experiment).

Abbreviations: CLSM, confocal laser scanning microscopy; HANP, hydroxyapatite nanoparticle; HSF, human epidermal fibroblasts. 
A

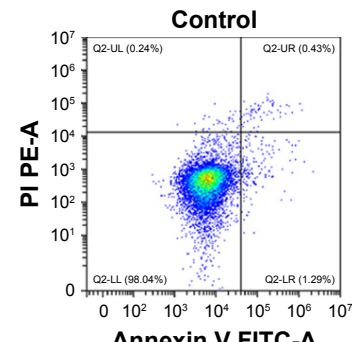

Annexin V FITC-A

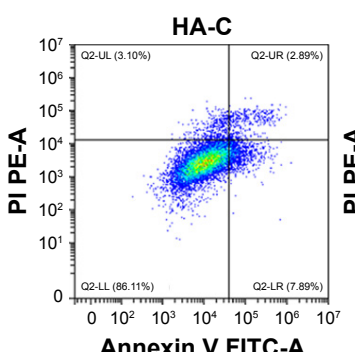

Annexin V FITC-A

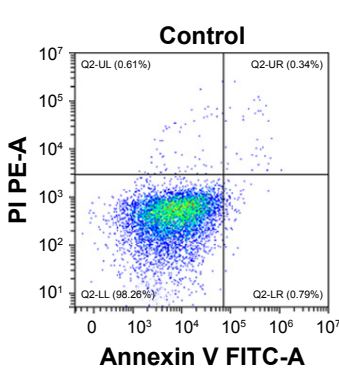

Annexin V FITC-A

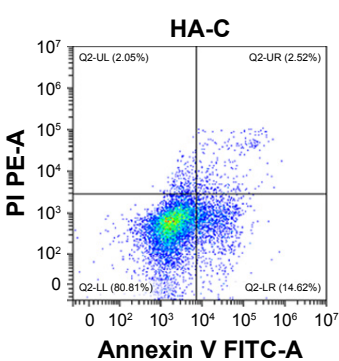

Day 1

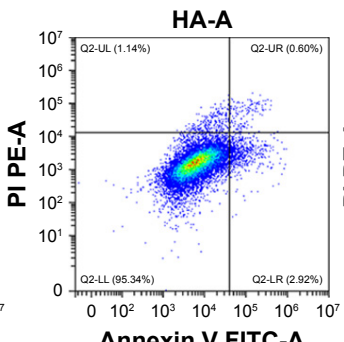

Annexin V FITC-A

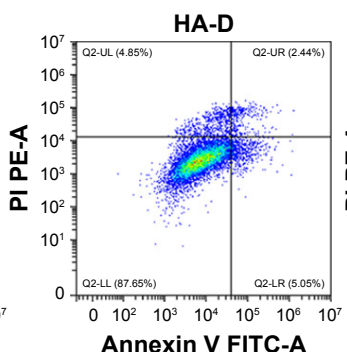

Annexin V FITC-A

Day 3

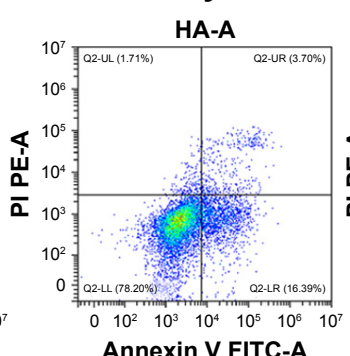

Annexin V FITC-A

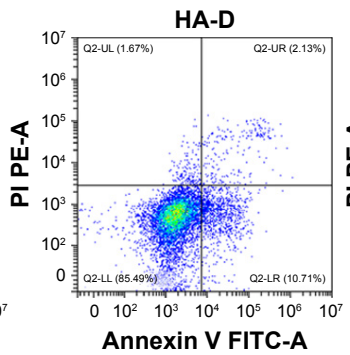

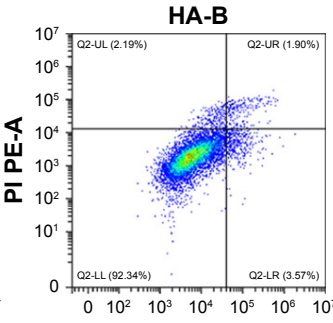

Annexin V FITC-A

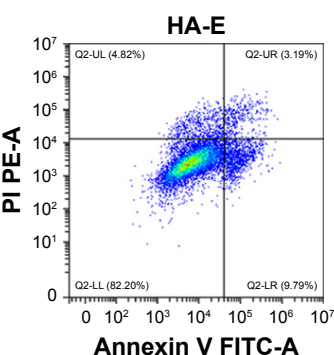

Annexin V FITC-A
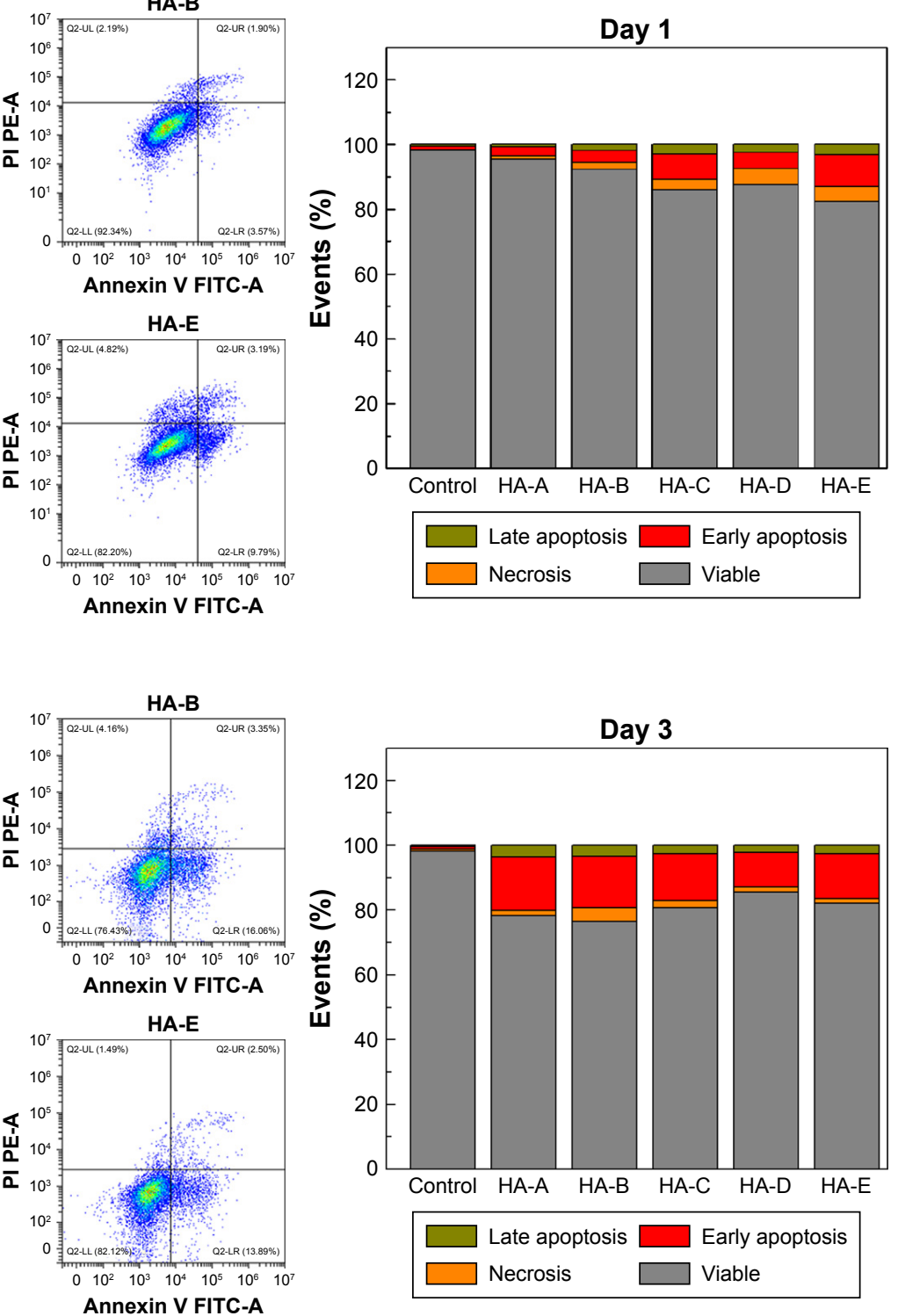

Figure 5 (A) Density maps of FITC Annexin V apoptosis detection results and (B) the rates of apoptosis and necrosis obtained by double-staining with Annexin V-FITC/PI of $\mathrm{A} 375$ cells after culturing with various HANPs at the concentration of $200 \mu \mathrm{g} / \mathrm{mL}$ for I and 3 days (three duplicates for each experiment).

Abbreviations: FITC, fluorescein isothiocyanate; PI, propidium iodide; HANP, hydroxyapatite nanoparticle.

concentration of $200 \mu \mathrm{g} / \mathrm{mL}$ for 1 and 3 days. Caspases are tightly related to cell apoptosis. ${ }^{26,37,38}$ Compared with the control group, three caspase genes (caspase-3, caspase-8, and caspase-9) were significantly up-regulated at day 1 by all the HANPs. Relatively, HA-A showed weaker ability to up-regulate the caspase gene expressions than other HANPs. At day 3, their expressions decreased sharply, but caspase-3 and caspase-9 still had higher expressions in some experimental groups. Besides caspases, Bax, Bcl-2, and p53 also played the active roles in cell apoptosis. ${ }^{39}$ Compared with the control group, Bax gene had slightly elevated expressions in some experimental groups at day 1 . But at day 3 , its expression in all the experimental groups, especially in HA-E was highly up-regulated. As for Bcl-2, it had much higher expression in the experimental groups except for HA-A at day 1 . At day 3, its gene expression decreased sharply, but still had obvious up-regulation in the experimental groups, especially in HA-E. As for p53, it always showed highly up-regulated gene expressions in the experimental groups at day 1 and 3 .

Figure 6B shows the apoptosis-related gene expressions in HSF cells after culturing with various HANPs at the concentration of $200 \mu \mathrm{g} / \mathrm{mL}$ for 1 and 3 days. It could be seen that compared with the control group, almost all the tested 
A
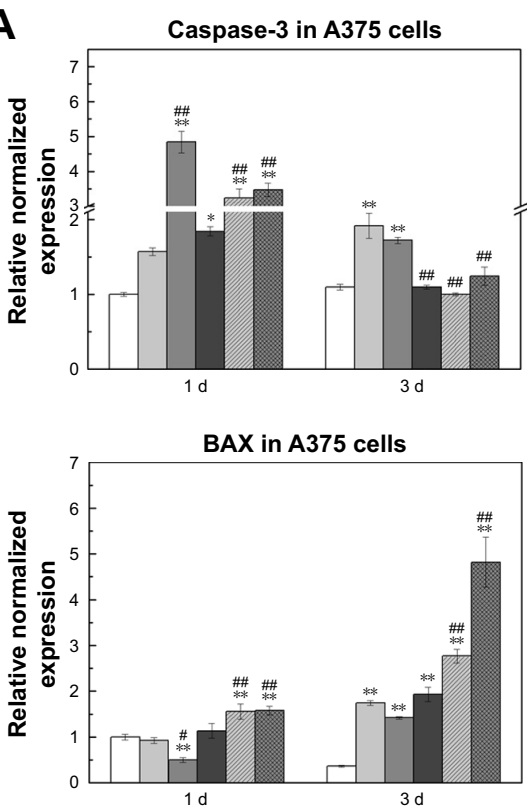

B

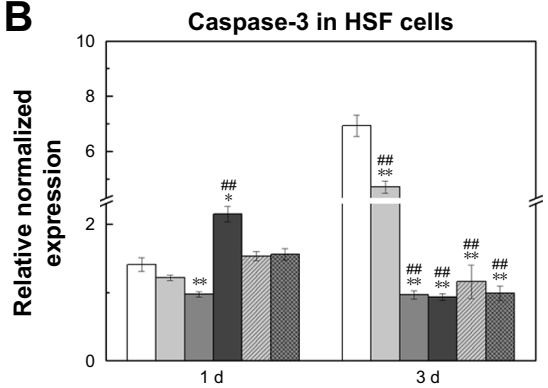

BAX in HSF cells

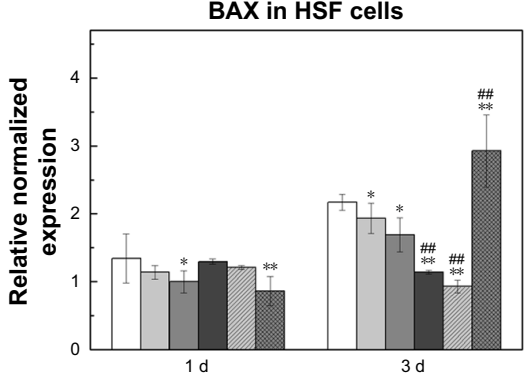

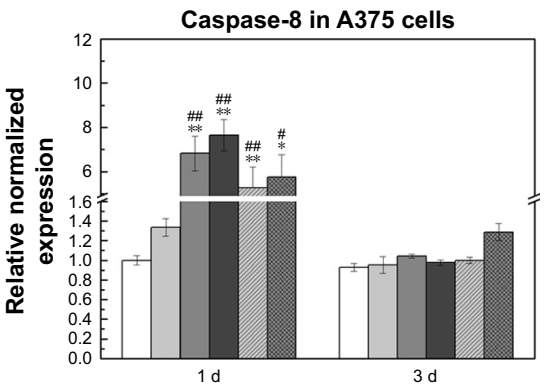
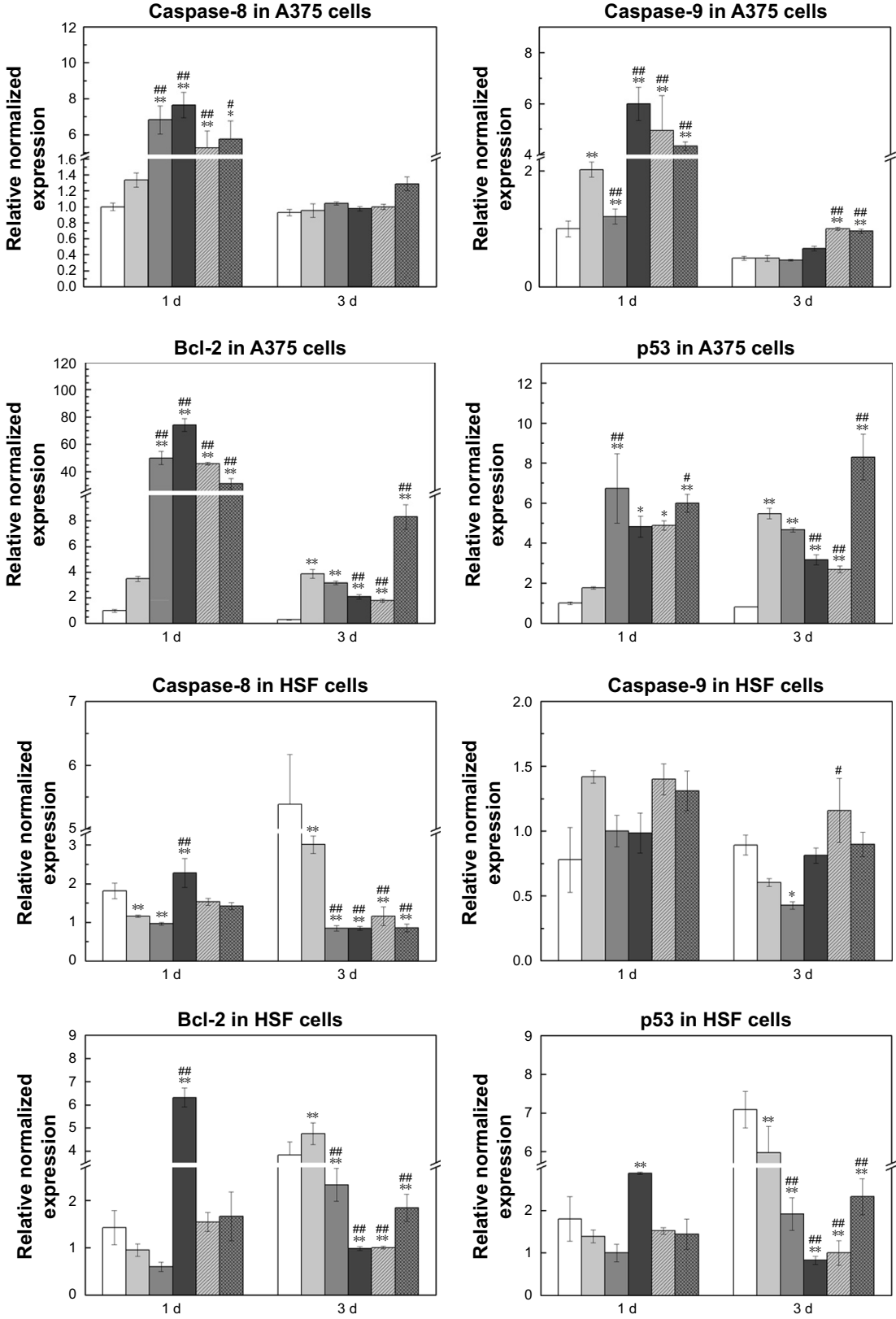

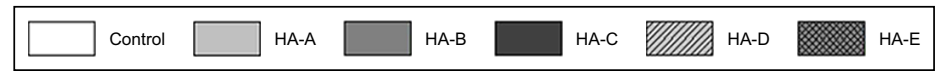

Figure 6 Apoptosis-related gene expressions in A375 (A) and HSF (B) cells after culturing with various HANPs at the concentration of $200 \mu \mathrm{g} / \mathrm{mL}$ for I and 3 days ( $\mathrm{n}=3$; vs control group, $* P<0.05$, $* * P<0.01$; vs $H A-A,{ }^{*} P<0.05,{ }^{\# P}<0.0$ I).

Abbreviations: HANP, hydroxyapatite nanoparticle; HSF, human epidermal fibroblasts.

genes showed no significant up-regulation in the experimental groups except HA-C. At day 1, the expressions of caspase-3, caspase-8, Bcl-2, and p53 genes were up-regulated to various extents by HA-C.

\section{Tumor tissue growth}

After in vivo injection of the suspensions of HANPs and A375 cells, the formation of tumor tissue was observed, and the volume changes with time prolongation were recorded. Figure 7 shows the volume change of the formed tumor tissue in nude mice with the prolongation of the feeding time. In the control group, the formed tumors could be observed clearly at day 7 , and then grew sharply. However, in the two experimental groups, the formation of tumor tissue was delayed obviously. After day 11, the tumor tissue formed and then grew up at a relatively lower speed. At each time point, the volume of the formed tumor tissue in HA-A or HA-C group was always smaller than that in the control group, indicating that both 
A
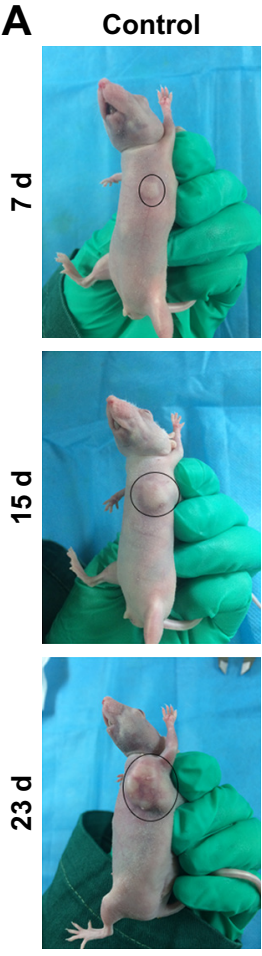

HA-A
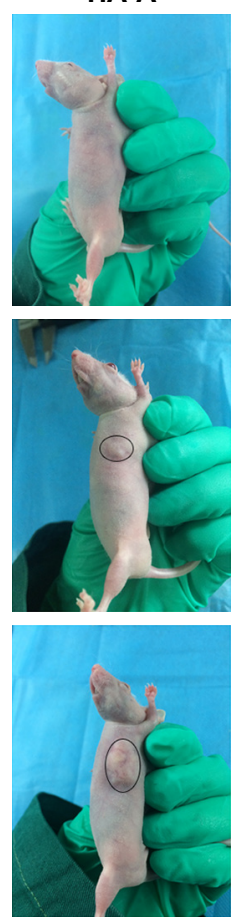

HA-C
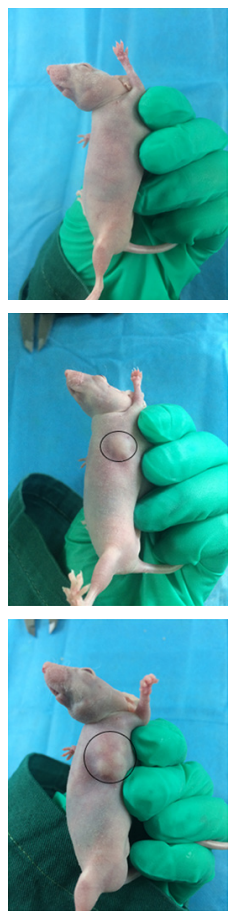

B

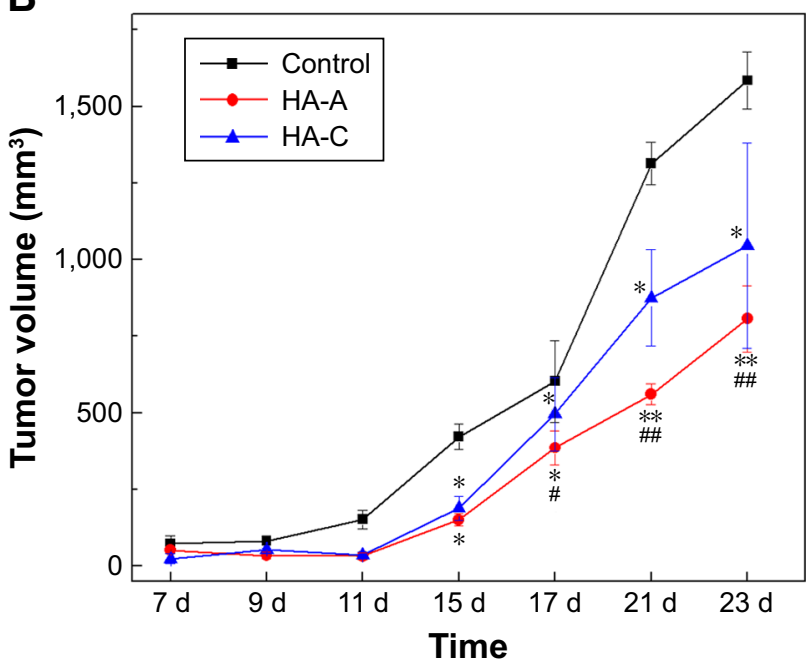

Figure 7 (A) Macroscopic observation for the growth of tumor tissue in nude mice. control group, ${ }^{* P}<0.05,{ }^{* * P}<0.0$ I; vs HA-C, ${ }^{*} P<0.05,{ }^{\#} P<0.0$ I).

HANPs could inhibit the growth of tumor tissue. At the same time, both HANPs showed the different inhibition effect on tumor tissue growth. HA-A presented better efficiency than HA-C. At day 23, the inhibition ratios of HA-A and HA-C for tumor tissue growth were $49.1 \%$ and $34.0 \%$, respectively.

\section{Discussion}

So far, melanoma remains one of the world's clinical treatment challenges. The conventional therapy is surgical resection supplemented with chemotherapy, which could lead to severe toxic and adverse effects on patients. Besides, some drugs, such as metformin, ${ }^{40}$ were also used for treating melanoma in clinic, but the current study showed that melanoma could have high tolerance to these drugs. In recent years, the rapid development of nanotechnology and nanomedicine could provide a new idea for the treatment for melanoma.

The Se NPs prepared by Chen et al using the wakame polysaccharide solution could induce apoptosis of A375 cells. ${ }^{41}$ Wang et al used CuO NPs to achieve good effect on inducing apoptosis of melanoma in vitro and in vivo. ${ }^{42}$ Meanwhile, other treatments, such as photothermal therapy ${ }^{43,44}$ and heat shock proteins combined with magnetic NPs ${ }^{45,46}$ were also used for killing melanoma as well as healing the wounds. However, although achieving good results, the aforementioned methods would inevitably kill some normal cells during the treatments and thus have an adverse impact on the local tissue repair. Therefore, it is quite necessary to find out a safer method to treat melanoma.

In 1993, Aoki et al and Kano et al first reported the in vitro anti-tumor effect of HANPs by inhibiting the proliferation of Ca-9 tumor cells. ${ }^{16,17}$ Afterward, HANPs received much attention as an anti-tumor material. In the past two decades, there were lots of literatures that reported the positive effects of HANPs on the proliferation inhibition or apoptosis of various tumor cells, including hepatoma cells, ${ }^{16-18}$ osteosarcoma cells, ${ }^{19-21}$ lung cancer cells, ${ }^{22,23}$ gastric cancer cells, ${ }^{24-26}$ etc. We previously found that HANPs had certain anti-melanoma effect by inhibiting the proliferation of A875 cells. ${ }^{29}$ In the present study, we further investigated the influences of the material factors on the anti-melanoma effects of HANPs by in vitro and in vivo evaluation.

Five HANPs were synthesized by using a wet chemical method in combination with polymer template and appropriate post-treatment. According to the results of XRD and FTIR tests (Figure 1), the as-prepared five HANPs were all pure HA. However, they exhibited different material features (Table 3), including morphology, size, crystallinity, etc. The in vitro cellular experiments confirmed that all the five HANPs had certain toxicity for A375 cells, but they showed no adverse or even promoting effect on the proliferation of normal HSF cells (Figure 3; Table 4). This selective inhibition on the proliferation of tumor cells was also reported in 
some previous literatures..$^{27,47,48}$ For example, Sun et al found that compared with normal human bronchial epithelial cells (16HBE), the rod-shaped HANPs had the selective growth inhibition and apoptosis on human lung cancer cells (A549) by mitochondrial-targeted pathway. ${ }^{25}$

In accordance with the previous studies, our results also showed that the cell viability was dependent on the concentration of HANPs. ${ }^{18,24,25,27}$ However, the viability of A375 melanoma cells did not always decrease with the increase in the concentration of HANPs. At day 3, compared with 100 and $400 \mu \mathrm{g} / \mathrm{mL}, 200 \mu \mathrm{g} / \mathrm{mL}$ of HANPs almost in each group exhibited higher inhibition effect on the viability of A375 cells (Figure 3A). This might be ascribed to the aggregation of HANPs in the media, which could be influenced by the concentration of the NPs. The increased particle aggregation in $400 \mu \mathrm{g} / \mathrm{mL}$ of HANPs could weaken the interactions between A375 cells and HANPs, leading to the decreased viability inhibition of the NPs on the cells. This phenomenon was also reported in some previous studies. ${ }^{22,49}$ However, in order to further verify it, a wider range of HANPs concentration should be selected to investigate the concentration-dependent inhibition on cell viability in future work. After treatment with $200 \mu \mathrm{g} / \mathrm{mL}$ of HANPs (Table 4), the as-prepared five HANPs showed different inhibitory effect on the viability of A 375 cells, in the order of HA-A $>$ HA-B $\approx$ HA-C $\approx$ HA-D $>$ HA-E. The lowest cell viability was only $34.90 \%$, indicating the excellent anti-melanoma effect of HA-A.

It is well known that cell death is caused by two different molecular mechanisms, ie, necrosis and apoptosis. Necrosis is a disorderly death of cells caused by strong physicochemical or biological factors. ${ }^{50}$ Apoptosis is a programmed death of cells caused by DNA fragmentation. ${ }^{51}$ After treating the cells with $200 \mu \mathrm{g} / \mathrm{mL}$ of HANPs, the nucleus of A375 cells had obvious morphological change and presented the apoptosis features, However, HSF cells were not observed to have obvious nuclear morphological change (Figure 4), indicating that the HANPs did not induce the apoptosis of normal fibroblasts. The flow cytometry tests further verified that all the HANPs could induce the apoptosis of A375 cells to some extent, and the relatively higher apoptosis rates of A375 cells were found in HA-A (20.10\%) and HA-B $(19.41 \%)$ at day 3 .

It is well known that the morphology of HANPs had a certain correlation with tumor cell apoptosis. ${ }^{27,52-54}$ Laquerriere et al reported that needle-shaped HANPs had stronger cytotoxicity than other morphologies of HANPs. ${ }^{52,53}$ The influence of the morphology of HANPs on melanoma cells was also evaluated in the present study. The as-prepared five HANPs in the form of granules (HA-A and HA-D), rods (HA-B and HA-C), and needles (HA-E) all promoted the apoptosis of A375 cells to some extent (Figure 5). Relatively, granular HANPs (HA-A) presented better effect on inducing the apoptosis of A375 cells. We speculated that other material factors could have an effect on the apoptosis of A375 cells. Comparing with other HANPs, granular HANPs (HA-A) had higher SSA and smaller particle size (Table 3 ), and could be more easily absorbed by tumor cells. Cui et al prepared three HANPs with different particle size, and they found that L200-HANPs with smallest size and highest SSA exhibited strongest toxicity to MGC80-3 tumor cells. ${ }^{27}$ Qi et al reported that small size of chitosan NPs had strong apoptosis induction of Sarcoma-180 and H22 tumor cells. ${ }^{54}$

Our results confirmed that the crystallinity of HANPs was also an important factor for inducing the apoptosis of tumor cells, as was seldom mentioned in previous studies. Among the as-prepared five HANPs, HA-A had the lowest crystallinity but the highest inhibitory effect on the viability of A375 cells (Tables 3 and 4). The possible reason was that low crystallinity of HANPs could release $\mathrm{Ca}^{2+}$ more efficiently. It is known that $\mathrm{Ca}^{2+}$ plays an important role in almost all cellular processes, especially cell proliferation and apoptosis. ${ }^{55}$ The proliferation of tumor cells is greatly affected by the change in the $\mathrm{Ca}^{2+}$ concentration of the surrounding environment. ${ }^{56}$ Generally, intracellular $\mathrm{Ca}^{2+}$ maintains a relatively low level. When penetrating into the cells, HANPs would release $\mathrm{Ca}^{2+}$ into the cytoplasm; this could disrupt intracellular $\mathrm{Ca}^{2+}$ homeostasis and have an adverse impact on cellular metabolism. ${ }^{57,58}$ The low crystallinity of HA-A released more $\mathrm{Ca}^{2+}$ and exhibited high cytotoxicity of A375 cells. However, it showed no inhibitory effect on the viability of normal HSF cells, same as other four HANPs. This could be attributed to the higher ability of normal cells to regulate $\mathrm{Ca}^{2+}$ balance than that of tumor cells. Tang et al evaluated the intracellular $\mathrm{Ca}^{2+}$ of MGC80-3, HepG2, HeLa, and normal hepatocytes (L-02) after cultured with HANPs, and the results showed that $\mathrm{Ca}^{2+}$ levels in tumor cells were unrecoverable, while normal cells could reduce $\mathrm{Ca}^{2+}$ to baseline level. ${ }^{59}$ On the other hand, it should be noted that although having a little higher crystallinity and similar $\mathrm{Ca}^{2+}$ release, HA-E exhibited lower inhibitory effect on the viability of A375 melanoma cells. The needle-shaped HA-E could form bigger aggregation of NPs in the solution than granular HA-A. Therefore, comparing with HA-E, HA-A could be absorbed by tumor cells more easily, leading to its higher viability inhibition on the cells.

The previous studies revealed that HANPs could penetrate into the cells by endocytosis. ${ }^{60-62}$ Our results indicated 
that the as-prepared five HANPs were all negatively charged, with similar zeta potentials. It is known that cell membrane was also electronegative, which could impede the approach of HANPs through the electrostatic repulsion. But in fact, it did not hinder the uptake of electronegative NPs by tumor cells. Patil et al reported that the negatively charged cerium oxide NPs were preferentially devoured by adenocarcinoma lung cells (A549) compared with positively charged ones. ${ }^{60}$ Villanueva et al reported that among the four differently charged iron oxide NPs, only the negatively charged ones were effectively absorbed by human cervical carcinoma cells (Hela) and showed some potential toxicity. ${ }^{61}$ Yin et al reported that HANPs with surface electronegativity could be efficiently taken up by Bel-7402 cells. ${ }^{62}$ Generally accepted, the endocytosis of negatively charged NPs by tumor cells was dependent on the local positively charged regions occurred on the cell membrane, which electrostatically attracts the NPs. ${ }^{60}$

Previously, the molecular mechanism of HANPs inducing apoptosis of tumor cells selectively has been widely investigated. ${ }^{63}$ Generally reported, after culturing with HANPs, apoptosis of tumor cells could be triggered by both the exogenous pathway from the death receptor and the endogenous pathway from mitochondria. ${ }^{26,63}$ The activation of caspase cascade plays an important role in the apoptosis of tumor cells. ${ }^{26,37,38}$ The endogenous apoptotic pathway causes caspase- 9 to be activated by mitochondrial damage, and the exogenous apoptotic pathway activates caspase- 8 by recruiting a death-inducing signaling complex. ${ }^{64}$ Both pathways subsequently activate the apoptosis-executing factor caspase-3, which ultimately leads to the apoptosis of tumor cells. Our results of PCR analysis (Figure 6A) showed that after culturing with the as-prepared five HANPs for 1 day, the gene expressions of caspase- 3 , caspase- 8 , and caspase- 9 genes in A375 cells were all up-regulated. This indicated that both exogenous and endogenous apoptotic pathways were simultaneously involved in the apoptosis mechanism of A375 cells induced by HANPs.

It is known that as a transcriptional regulation factor, p53 plays an important role in cell apoptosis. The DNA damage could induce the elevated protein level of p53 in the cells, which would then regulate the downstream genes and finally induce cell apoptosis..$^{39,65}$ We examined the related gene expressions in A375 cells involving the p53-mediated apoptotic pathway, and the results (Figure 6A) showed that after culturing with the as-prepared five HANPs, p53 always had significantly up-regulated gene expression in the cells, and the gene expression of the downstream Bax with proapoptotic function was also highly up-regulated at day 3 .
However, as an inhibitor of apoptosis, the gene expression of Bcl-2 was also up-regulated by the HANPs. Therefore, the p53-Bax signaling pathway was also initiated in the course of the apoptosis of A375 cells induced by HANPs.

For the expressions of apoptosis-related genes in A375 melanoma cells at day 1, HA-A showed relatively lower up-regulating effect than other HANPs groups. However, like other groups of HANPs, HA-A exhibited better proapoptosis effect on the cells. One possible reason could be due to the special morphology and size of HA-A. As aforementioned, the granular and smaller HA-A could have better membrane permeability than other HANPs and then cause the apoptosis of the cells. More importantly, comparing with the gene expressions, the synthesis and secretion of the apoptosisrelated proteins in the cells regulated by the HANPs would play more decisive role in the cell apoptosis. Therefore, more evidences need be found to reveal the definite mechanism by which HANPs induce apoptosis of A375 melanoma cells.

Likely, the aforementioned apoptosis-related gene expressions in HSF cells were also evaluated by the PCR analysis (Figure 6B). Almost all the tested genes were not activated in HSF cells by HANPs, as could be the main reason that the HANPs only inhibited the viability of A375 melanoma cells and induced the apoptosis of the cells (Figures 3-5; Table 4).

According to the in vitro evaluation, the as-prepared five HANPs exhibited different suppression effect on the viability of A375 melanoma cells. To further verify the in vivo antimelanoma effect of HANPs, two HANPs (HA-A and HA-C) with different efficiency on inhibiting the viability of A375 cells were selected as the experimental materials for in vivo animal study. The results (Figure 7) confirmed that both HANPs delayed the formation of tumor tissue in the nude mice about 1 week. Moreover, the growth rate of the formed tumor tissue was also inhibited by the HANPs, and HA-A showed stronger inhibitory effect than HA-C. The result was in accordance with the in vitro evaluation, in which HA-A induced the lower viability of A375 melanoma cells than HA-C (Table 4).

For HANPs, their physicochemical properties are influenced by each other. Therefore, it is hard to reveal how each material factor inhibits the viability of the melanoma cells or induces the apoptosis of the cells. Therefore, finding out the optimized HANPs for tumor suppression needs much work and advanced technology, such as materials genome initiative based on big data analytics. But anyway, our in vitro and in vivo experiments verified the anti-melanoma effect of HANPs, as could provide a new idea for the clinical treatment of melanoma. 


\section{Conclusion}

The present study verified the anti-melanoma effect of HANPs by the in vitro and in vivo experiments, while they did not inhibit and even promote the viability of the normal fibroblasts. The physicochemical properties of HANPs, including morphology, size, SSA, crystallinity, and so on, played important role in inhibiting the viability of A375 cells and inducing the apoptosis of the cells. Among the as-prepared five HANPs, HA-A with granular shape, smaller size, higher SSA, and lower crystallinity presented better anti-melanoma efficiency. The apoptosis-related genes were up-regulated in A375 cells but not in HSF cells by the HANPs; this could be the reason that HANPs had the selective inhibition on the viability of melanoma cells. Therefore, HANPs could be an excellent candidate for the clinical treatment of melanoma.

\section{Acknowledgment}

This work was financially supported by National Key Research and Development Program of China (2017YFB0702600, 2017YFB0702603), the National Natural Science Foundation of China (81801852) and the "111" Project of China (B16033).

\section{Disclosure}

The authors report no conflicts of interest in this work.

\section{References}

1. Köllisch G, Kalali BN, Voelcker V, et al. Various members of the Toll-like receptor family contribute to the innate immune response of human epidermal keratinocytes. Immunology. 2005;114(4):531-541.

2. Grimstad O, Pukstad B, Stenvik J, Espevik T. Oligodeoxynucleotides inhibit Toll-like receptor 3 mediated cytotoxicity and CXCL8 release in keratinocytes. Exp Dermatol. 2012;21(1):7-12.

3. Konstantinov NK, Ulff-Møller CJ, Dimitrov S. Histone variants and melanoma: facts and hypotheses. Pigment Cell Melanoma Res. 2016; 29(4):426-433.

4. Paluncic J, Kovacevic Z, Jansson PJ, et al. Roads to melanoma: key pathways and emerging players in melanoma progression and oncogenic signaling. Biochim Biophys Acta. 2016;1863(4):770-784.

5. Rigel DS, Russak J, Friedman R. The evolution of melanoma diagnosis: 25 years beyond the ABCDs. CA Cancer J Clin. 2010;60(5):301-316.

6. Lens MB, Dawes M. Global perspectives of contemporary epidemiological trends of cutaneous malignant melanoma. Br J Dermatol. 2004; 150(2):179-185.

7. Prasad ML, Patel SG, Huvos AG, Shah JP, Busam KJ. Primary mucosal melanoma of the head and neck. Cancer. 2004;100(8):1657-1664.

8. Finger PT. Radiation therapy for choroidal melanoma. Surv Ophthalmol. 1997;42(3):215-232.

9. Hall HI, Miller DR, Rogers JD, Bewerse B. Update on the incidence and mortality from melanoma in the United States. J Am Acad Dermatol. 1999;40(1):35-42.

10. Weyers W, Euler M, Diaz-Cascajo C, Schill WB, Bonczkowitz M. Classification of cutaneous malignant melanoma. Cancer. 1999;86(2): 288-299.

11. Mukherji B, Chakraborty NG. Immunobiology and immunotherapy of melanoma. Curr Opin Oncol. 1995;7(2):175-184.
12. Ettinghausen SE, Rosenberg SA. Immunotherapy and gene therapy of cancer. Advances in surgery. 1995;28:223-254.

13. Dorozhkin S. Calcium orthophosphates in nature, biology and medicine. Materials. 2009;2(2):399-498.

14. Tang Z, Li X, Tan Y, Fan H, Zhang X. The material and biological characteristics of osteoinductive calcium phosphate ceramics. Regen Biomater. 2018;5(1):43-59.

15. Hong Y, Fan H, Li B, Guo B, Liu M, Zhang X. Fabrication, biological effects, and medical applications of calcium phosphate nanoceramics. Mate Sci Eng R Rep. 2010;70(3-6):225-242.

16. Aoki H, Ohgaki M, Kano S. Effects of Adriacin-absorbing hydroxyapatite-sol on Ca-9 cell growth. Rep Inst Med Dent Eng. 1993;27:39-44.

17. Kano S, Yamazaki A, Otsuka R, Ohgaki M, Akao M, Aoki H. Application of hydroxyapatite-sol as drug carrier. Biomed Mater Eng. 1994; 4(4):283.

18. Yuan Y, Liu C, Qian J, Wang J, Zhang Y. Size-mediated cytotoxicity and apoptosis of hydroxyapatite nanoparticles in human hepatoma HepG2 cells. Biomaterials. 2010;31(4):730-740.

19. Bauer IW, Li SP, Han YC, Yuan L, Yin MZ. Internalization of hydroxyapatite nanoparticles in liver cancer cells. JMater Sci Mater Med. 2008; 19(3):1091-1095.

20. Li S, Hu S, Yan Y, Wang Y. Investigation of Hap nanoparticles absorbed by hepatoma cells in vitro. J Wuhan Univ Technol. 2007;22(2):288-290.

21. Cai Y, Liu Y, Yan W, et al. Role of hydroxyapatite nanoparticle size in bone cell proliferation. J Mater Chem. 2007;17(36):3780.

22. Qing F, Wang Z, Hong Y, et al. Selective effects of hydroxyapatite nanoparticles on osteosarcoma cells and osteoblasts. J Mater Sci Mater Med. 2012;23(9):2245-2251.

23. Hengartner MO. The biochemistry of apoptosis. Nature. 2000;407(6805): 770-776.

24. Chen MH, Hanagata N, Ikoma T, et al. Hafnium-doped hydroxyapatite nanoparticles with ionizing radiation for lung cancer treatment. Acta Biomater. 2016;37:165-173.

25. Sun Y, Chen Y, Ma X, et al. Mitochondria-targeted hydroxyapatite nanoparticles for selective growth inhibition of lung cancer in vitro and in vivo. ACS Appl Mater Interfaces. 2016;8(39):25680-25690.

26. Chen X, Deng C, Tang S, Zhang M. Mitochondria-dependent apoptosis induced by nanoscale hydroxyapatite in human gastric cancer SGC7901 cells. Biol Pharm Bull. 2007;30(1):128-132.

27. Cui X, Liang T, Liu C, Yuan Y, Qian J. Correlation of particle properties with cytotoxicity and cellular uptake of hydroxyapatite nanoparticles in human gastric cancer cells. Mater Sci Eng C Mater Biol Appl. 2016; $67: 453-460$

28. Li J, Yin Y, Yao F, Zhang L, Yao K. Effect of nano- and microhydroxyapatite/chitosan-gelatin network film on human gastric cancer cells. Mater Lett. 2008;62(17-18):3220-3223.

29. Li B, Guo B, Fan H, Zhang X. Preparation of nano-hydroxyapatite particles with different morphology and their response to highly malignant melanoma cells in vitro. Appl Surf Sci. 2008;255(2):357-360.

30. Stojanović Z, Veselinović L, Marković S, Ignjatović N, Uskoković D. Hydrothermal synthesis of nanosized pure and cobalt-exchanged hydroxyapatite. Mater Manuf Processes. 2009;24(10-11):1096-1103.

31. Utara S, Klinkaewnarong J. Preparation of nano-hydroxyapatite particles by ultrasonic method at $25 \mathrm{kHz}$ using natural rubber latex as a templating agent. Chiang Mai J Sci. 2015;43(2):320-328.

32. Tomayko MM, Reynolds CP. Determination of subcutaneous tumor size in athymic (nude) mice. Cancer Chemother Pharmacol. 1989;24(3): $148-154$.

33. Thamaraiselvi K, Rajeswari S. Synthesis of hydroxyapatite that mimic bone mineralogy. Trends Biomater Artif Organs. 2006;19(2):81.

34. Featherstone JD, Mayer I, Driessens FC, Verbeeck RM, Heijligers HJ. Synthetic apatites containing $\mathrm{Na}, \mathrm{Mg}$, and $\mathrm{CO} 3$ and their comparison with tooth enamel mineral. Calcif Tissue Int. 1983;35(2):169-171.

35. Bayraktar D, Tas AC. Chemical preparation of carbonated calcium hydroxyapatite powders at $37^{\circ} \mathrm{C}$ in urea-containing synthetic body fluids. J Eur Ceram Soc. 1999;19(13-14):2573-2579. 
36. Emanuele S, Lauricella M, Carlisi D, et al. SAHA induces apoptosis in hepatoma cells and synergistically interacts with the proteasome inhibitor bortezomib. Apoptosis. 2007;12(7):1327-1338.

37. Budihardjo I, Oliver H, Lutter M, Luo X, Wang X. Biochemical pathways of caspase activation during apoptosis. Annu Rev Cell Dev Biol. 15(1):269.

38. Boatright KM, Salvesen GS. Mechanisms of caspase activation. Curr Opin Cell Biol. 2003;15(6):725-731.

39. Tay CY, Fang W, Setyawati MI, et al. Nano-hydroxyapatite and nano-titanium dioxide exhibit different subcellular distribution and apoptotic profile in human oral epithelium. ACS Appl Mater Interfaces. 2014;6(9):6248-6256.

40. Tomic T, Botton T, Cerezo M, et al. Metformin inhibits melanoma development through autophagy and apoptosis mechanisms. Cell Death Dis. 2011;2(9):e199.

41. Chen T, Wong YS, Zheng W, Bai Y, Huang L. Selenium nanoparticles fabricated in Undaria pinnatifida polysaccharide solutions induce mitochondria-mediated apoptosis in A375 human melanoma cells Colloids Surf B Biointerfaces. 2008;67(1):26-31.

42. Wang Y, Yang F, Zhang HX, et al. Cuprous oxide nanoparticles inhibit the growth and metastasis of melanoma by targeting mitochondria. Cell Death Dis. 2013;4(8):e783.

43. Yu Q, Han Y, Wang X, et al. Copper silicate hollow MicrospheresIncorporated scaffolds for chemo-photothermal therapy of melanoma and tissue healing. ACS Nano. 2018;12(3):2695-2707.

44. Wang X, Lv F, Li T, et al. Electrospun micropatterned nanocomposites incorporated with $\mathrm{Cu}_{2} \mathrm{~S}$ Nanoflowers for skin tumor therapy and wound healing. ACS Nano. 2017;11(11):11337-11349.

45. Ito A, Saito H, Mitobe K, et al. Inhibition of heat shock protein 90 sensitizes melanoma cells to thermosensitive ferromagnetic particlemediated hyperthermia with low Curie temperature. Cancer Sci. 2009; 100(3):558-564

46. Ito A, Matsuoka F, Honda H, Kobayashi T. Antitumor effects of combined therapy of recombinant heat shock protein 70 and hyperthermia using magnetic nanoparticles in an experimental subcutaneous murine melanoma. Cancer Immunol Immunother. 2004;53(1):26-32.

47. Kramer E, Podurgiel J, Wei M. Control of hydroxyapatite nanoparticle morphology using wet synthesis techniques: reactant addition rate effects. Mater Lett. 2014;131:145-147.

48. Zhang H, Darvell BW. Morphology and structural characteristics of hydroxyapatite whiskers: effect of the initial $\mathrm{Ca}$ concentration, $\mathrm{Ca} / \mathrm{P}$ ratio and pH. Acta Biomater. 2011;7(7):2960-2968.

49. Zhao H, Wu C, Gao D, et al. Antitumor effect by hydroxyapatite nanospheres: activation of mitochondria-dependent apoptosis and negative regulation of phosphatidylinositol-3-kinase/protein kinase B pathway. ACS Nano. 2018;12(8):7838-7854.
50. Wang L, Zhou G, Liu H, et al. Nano-hydroxyapatite particles induce apoptosis on MC3T3-E1 cells and tissue cells in SD rats. Nanoscale. 2012;4(9):2894-2899.

51. Kerr JFR. History of the events leading to the formulation of the apoptosis concept. Toxicology. 2002;181-182(24):471-474.

52. Laquerriere P, Grandjean-Laquerriere A, Jallot E, Balossier G, Frayssinet P, Guenounou M. Importance of hydroxyapatite particles characteristics on cytokines production by human monocytes in vitro. Biomaterials. 2003;24(16):2739-2747.

53. Grandjean-Laquerriere A, Laquerriere P, Laurent-Maquin D, Guenounou M, Phillips TM. The effect of the physical characteristics of hydroxyapatite particles on human monocytes IL-18 production in vitro. Biomaterials. 2004;25(28):5921-5927.

54. Qi L, Xu Z. In vivo antitumor activity of chitosan nanoparticles. Bioorg Med Chem Lett. 2006;16(16):4243-4245.

55. Clapham DE. Calcium signaling. Cell. 2007;131(6):1047-1058.

56. Schuller HM, Correa E, Orloff M, Reznik GK. Successful chemotherapy of experimental neuroendocrine lung tumors in hamsters with an antagonist of Ca2+/calmodulin. Cancer Res. 1990;50(5):1645.

57. Mattson MP, Chan SL. Calcium orchestrates apoptosis. Nat Cell Biol. 2003;5(12):1041-1043.

58. Motskin M, Wright DM, Muller K, et al. Hydroxyapatite nano and microparticles: correlation of particle properties with cytotoxicity and biostability. Biomaterials. 2009;30(19):3307-3317.

59. Tang W, Yuan Y, Liu C, Wu Y, Lu X, Qian J. Differential cytotoxicity and particle action of hydroxyapatite nanoparticles in human cancer cells. Nanomedicine. 2014;9(3):397-412.

60. Patil S, Sandberg A, Heckert E, Self W, Seal S. Protein adsorption and cellular uptake of cerium oxide nanoparticles as a function of zeta potential. Biomaterials. 2007;28(31):4600-4607.

61. Villanueva A, Cañete M, Roca AG, et al. The influence of surface functionalization on the enhanced internalization of magnetic nanoparticles in cancer cells. Nanotechnology. 2009;20(11):115103.

62. Yin M, Yin Y, Han Y, Dai H, Li S. Effects of uptake of hydroxyapatite nanoparticles into hepatoma cells on cell adhesion and proliferation. J Nanomater. 2014;2014(1):1-7.

63. Wang $\mathrm{Y}$, Wang $\mathrm{J}, \mathrm{Hao} \mathrm{H}$, et al. In vitro and in vivo mechanism of bone tumor inhibition by selenium-doped bone mineral nanoparticles. ACS Nano. 2016;10(11):9927-9937.

64. Fuchs Y, Steller H. Programmed cell death in animal development and disease. Cell. 2011;147(4):742-758.

65. Sun J, Ding T. P53 reaction to apoptosis induced by hydroxyapatite nanoparticles in rat macrophages. J Biomed Mater Res A. 2009;88(3) 673-679.
International Journal of Nanomedicine

\section{Publish your work in this journal}

The International Journal of Nanomedicine is an international, peerreviewed journal focusing on the application of nanotechnology in diagnostics, therapeutics, and drug delivery systems throughout the biomedical field. This journal is indexed on PubMed Central, MedLine, CAS, SciSearch $®$, Current Contents $\AA /$ Clinical Medicine,

\section{Dovepress}

Journal Citation Reports/Science Edition, EMBase, Scopus and the Elsevier Bibliographic databases. The manuscript management system is completely online and includes a very quick and fair peer-review system, which is all easy to use. Visit http://www.dovepress.com/ testimonials.php to read real quotes from published authors. 